\title{
From the eyes of the children: How an urban regeneration project could be?
}

\author{
Ebru KAMACI-KARAHAN, Bursa Technical University, Turkey
}

\begin{abstract}
In terms of their interactions with the social and physical environments, children are a unique community. While the majority of place-making processes fail to consider children and their needs, they are the most outspoken critics of the places in which they live. Recalling empowerment and inclusion, this study aims to examine children's perspectives (expectations, suggestions, problems, needs and perceptions, etc.) on the place-making processes, namely an urban regeneration project, by concerning them as users. As the stories and voices of participants are main concerns of the participatory approaches, walking interviews method have been conducted in this study. In Namık Kemal neighborhood (Bursa/Turkey), I have interviewed seven children ranging in age from seven to fourteen. Walking interviews were performed separately with children who lived in the gated-community developed by an urban transformation project and those who lived in the project's immediate zone. I aim to hear the authentic voices of the children (who directly and indirectly interact with the project)-about the project-generated social and physical environments; and restructure them from a broader socio-spatial perspective. Initially, the research highlights that if we -urban planners- want to make cities more humancentric, we must be unprejudiced and reconsider the role of the children.
\end{abstract}

\section{Keywords}

Inclusive Planning, Children, Participatory Research, Walking Interviews, Urban Regeneration

\section{Introduction}

While user-oriented urbanism has the potential to significantly improve people's lives, particularly those of disadvantaged and/or marginalized communities, such as women and children, inclusive urban planning seeks to integrate the various aspects of user-oriented urbanism throughout the planning lifecycle. Typically implemented through public participation, inclusive and equitable approaches prevail in contemporary urban planning (Liepa-Zemeša \& Hess, 2016). Given the current focus on sustainable and inclusive planning, practitioners must pay more attention to the value of their living space by individuals and communities (Evans \& Jones, 2011).

Children form a distinct community in their interactions with the environment. It is true that they are the most vocal critics of the areas in which they live; nonetheless, the bulk of place-making procedures ignore children and their interests. This statement will serve as the foundation for the rest of the paper. In the spirit of empowerment and inclusion, the purpose of this study is to investigate children's perspectives (expectations, recommendations, difficulties, needs, and perceptions, etc.) on place-making processes, specifically an urban regeneration project, by involving them as users. 
When working with children and other disadvantaged populations, participatory qualitative methods are more adaptable and versatile than traditional qualitative approaches. Because the stories and "voices" of participants are crucial to the design and goals of participatory approaches, walking interviews, one of the participatory action research methodologies, were used in this study.

I interviewed seven children ranging in age from seven to fourteen in the Namık Kemal neighborhood (Bursa/Turkey) with a low-perceived physical-quality of life. Separate walking interviews were conducted with children who lived in the gated community created by the urban redevelopment project and children who lived in the near vicinity of the project. Rather than asking what is missing in this project, what do you believe should be the "must-have uses in the project"? was inquired. By doing so, I hope to hear the authentic voices of the children (who interact with the project both directly and indirectly) regarding the social and physical settings created by the project, and to reorganize them from a broader socio-spatial viewpoint. In a similar vein, this method provided a thorough understanding of children's perceptions of urban regeneration. To begin, the study emphasizes that if we - urban planners - want to make cities more human-centric, we must be open-minded and re-examine the role of children.

The structure of the paper is as follows: the second chapter introduces the children to urban planning. The technique and data of the study are covered in Chapter three, and the research conclusions are shown in the next chapter. In the final chapter, concluding remarks, I re-examine the findings in depth and specify the research's future directions.

\section{Children in urban planning}

Kevin Lynch designed "Growing Up in Cities", in the 1970s' advocacy planning movements, the first comparative multi-country study on children's environments to include young children from low-income families in evaluating their own situations (Chatterjee, 2015). However, the image of the child and the view of childhood has profoundly changed in the last few decade (Quennerstedt \& Quennerstedt, 2014) and the ideology of child-centered life plays an important role in politics and place-making regarding the "child" and the "interest of the child" (James \& Prout, 2015). How can we ever expect to improve the lives of children and young people without hearing and understanding the quality of their lives? (Pople, Rees, Main, \& Bradshaw, 2015). In this respect, the insights from the experiences and prototyping have raised awareness of the needs of the children in the vision of the area regeneration plan; thus their visibility has increased as potential space users (Winge \& Lamm, 2019). Because of changes in childhood perspectives, a wave of literature has been created which exposes child participation in research (Salamon, 2015).

However, the ecological character of the development of children must be recognized, which is a multilevel, embedded and an evolving system made up of a variety of physical and social structures according to Bronfenbrenner (1979). In line with this ecological framework, the homes are part of the child's closest physical system and family and direct caregivers are part of the social context (Chatterjee, 2015). In various geographical contexts, wide-ranging, enduring and mutual social relations provide a child with enriching environmental conditions (Matthews 1999). In collaborative planning and construction with children, it is conducted a co-design process which is aim to provide insight into the children's point of view.

Children's skills and know-how (Tisdall \& Punch, 2012; Salamon, 2015) and children's expertise (Levy \& Thompson, 2015) were respected and encouraged children to discuss their own views, knowledge and opinions with confidence (Dunn et al., 2018). Winge and Lamm (2019) argued that children's commitment and perspectives help to create improved and better-informed public spaces in their communities. In their well-known study, they investigated how not just the child benefits the process and the outcome, but also help to involve a diverse range of local stakeholders in the discussion of its future design (Winge \& Lamm, 2019). In a similar vein, Chatterjee (2015) asked what can urban designers learn 
about children's use, slum-urban activities and children's perceptions about slum renovation and redevelopment in slum-urban spaces? In a study of children in degraded slum surroundings of Delhi (Chatterjee 2015), it was found that children's preferred spaces mainly include formal settings, such as well-kept parks nearby that allow nature contact and provide opportunities for social and playful interactions with friends. The study pointed out that cleanliness, security and friendliness of the slum's outdoor spaces are certainly important in improving children's health and well-being, but since slum kids are not limited to their slum exploration outdoors, plans to improve the slum will work better for children (Chatterjee 2015). In fact, the views of children are refreshing because often polarized stories are challenging (Dunn et al., 2018). While praiseworthy, the mantra that values voices of children are not simple in practical terms (Tisdall \& Punch, 2012).

\section{Methodology}

\subsection{Walking interview}

The methods of walking research are part of an increasing interest in active and participatory methods during recent years (Kowalewski \& Bartłomiejski, 2020). To study the relation between the self and the place, walking interviews are increasingly being used as a distinct qualitative research method (Evans \& Jones, 2011). As King and Woodroffe (2019) state that walking interview allows social researchers to learn about their participants' ties to place and social environments in their neighborhoods (King \& Woodroffe, 2019). Altered from sedentary interviews, walking interviews can produce both quantitative data on the routes travelled and better-known qualitative data derived from this discussion (Evans \& Jones, 2011).

Walking interviews produce richer data because interviewers are prompted by meanings and connections to their surroundings and are less inclined to try to give the "correct" answer (Evans \& Jones, 2011). Basically, the aim of this method is to provide an insight into the relationship between a participant and their surroundings (King \& Woodroffe, 2019). In a similar vein, it aims to give the researcher access to opinions and knowledge of a given geographical area of the participants (Evans \& Jones, 2011).

When designing walking research, the most crucial decision that researchers must make is whether the route is established by the interviewer or the interviewee (Evans \& Jones, 2011). If the researcher wishes to gather thoughts regarding specific buildings or roads, he or she may need to take an organized itinerary (Evans \& Jones, 2011). In this type of walking interview, the researcher walks along with the participant around a geographical place that the person has chosen which is connected to the topic under investigation (Clark \& Emmel, 2010). Basically, it is why I preferred to use this mode of walking interview in this pilot research.

\subsection{Study Area}

Namık Kemal neighborhood is approximately 2 kilometers from Bursa city center (see Figure 1). The establishment of the neighborhood where Albanian immigrants were settled dates back to the 1970s. The neighborhood, where mostly Albanian immigrants lived until the 2010s, is at the top of the living space preferences of Syrian and Afghan immigrants in Bursa today. The population of neighborhood is approximately 8.350, with 1300 households. The average cost of housing units rent per month is $1.500 \mathrm{TL}$ (200 US DOLAR). As can be seen in Figure 2, the physical quality of built-up areas and the maintenance level of living environment are relatively low. 


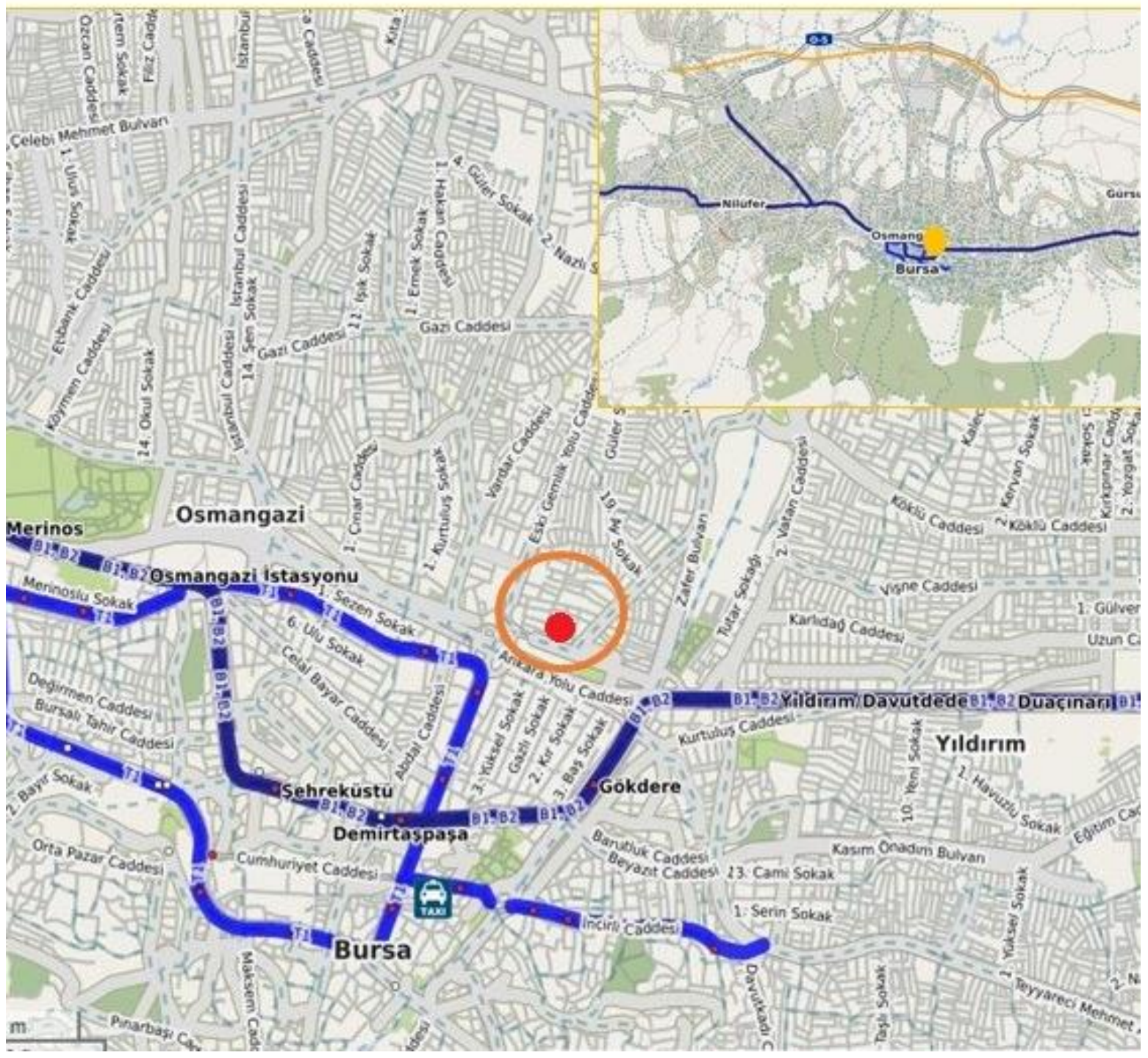

Figure 1. Location of surveyed-neighborhood (orange circle), the red dot shows the urban regeneration project surveyed and Blue lines present the sub-way and light-rail networks. Source: https://www.openstreetmap.org/search? query=zafer\%20mahallesi\%20Bursa\#map=14/40.1972/29.0799\&layers=0, accessed August 222021.

(a)

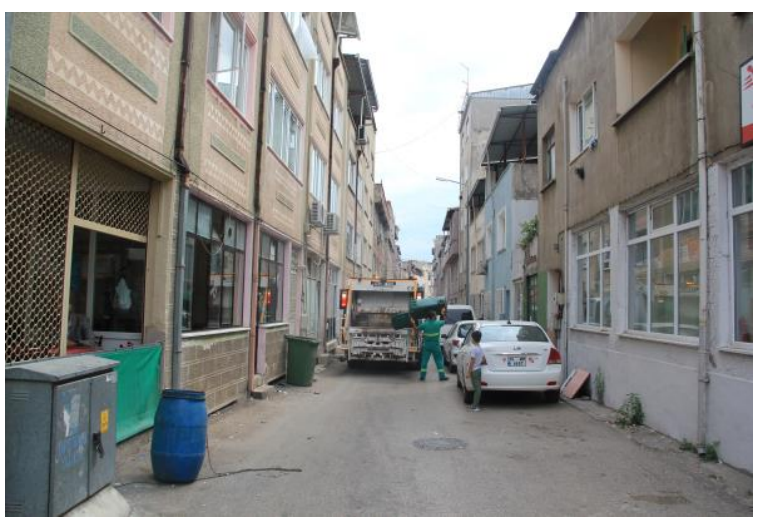

(b)

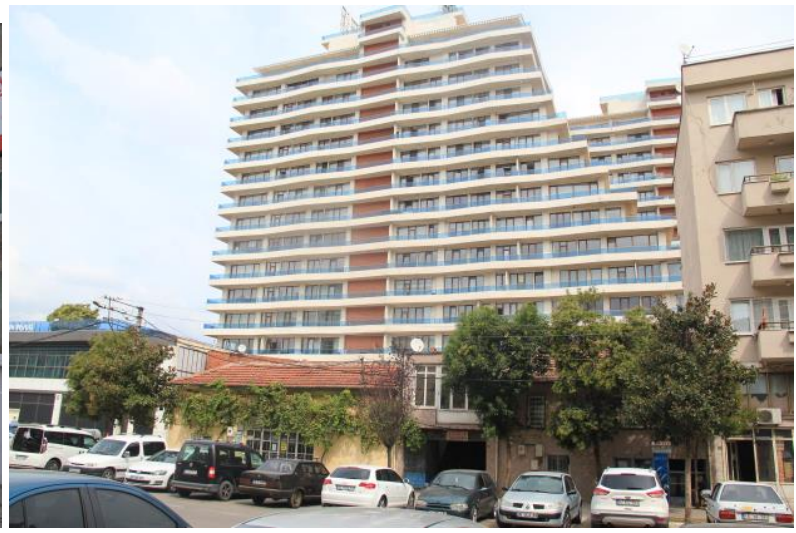

Figure 2. (a) Surroundings of the project, (b) the blocks of the urban regeneration project

Source: Author 


\subsection{Study participants}

As previously stated, I conducted a walking interview with seven children. Table 1 shows a demographic breakdown of study participants. Four of them live in the regeneration-project developed housing estate, while the others live nearby. They can all read and write, as well as communicate verbally. This article was written with permission from the ethics committee of Bursa Technical University in August, 2021; and it was carried out as a pilot study for a larger research project named "Socio-spatial structure and place-making processes: Transformation and differentiation".

\begin{tabular}{llll}
\hline ID & SEX & Age & Lived-year in neighborhood or the project \\
A_UR & Girl & 12 & 12 \\
B_UR & Boy & 9 & 6 \\
C_UR & Boy & 10 & 6 \\
D_UR & Boy & 14 & 12 \\
E_NUR & Girl & 14 & 14 \\
F_NUR & Boy & 12 & 12 \\
G_NUR & Boy & 7 & 7 \\
\hline
\end{tabular}

Table 1. Description of participants in survey

\section{The children as distinct-users}

If decision-making is to be fair and sustainable, it must take into account local histories and preferences of local communities, sensitively tying the past to the future (Evans \& Jones, 2011). Since children are a part of society, their ideas, experiences, preferences, needs, and demands should be considered as stakeholders in the design process. As previously mentioned, the study you are reading post-occupancy analyses this argument in the context of the urban regeneration project.

The most obvious result is that the newly created socio-spatial environment does not satisfy either the group living in the project or the group living in the project's immediate locality. At this point, the children are particularly focused on the project architecture. This new block, which in horizontal and vertical contexts is incompatible with the existing building environment, draws special attention to its mass area See Figure 3. One child (F_NUR) described this disparity as follows: This building is so massive that the sun is no longer entering our house. Another child (C_UR) also stated: All is concrete here, even the playgrounds. See Figure 4. 

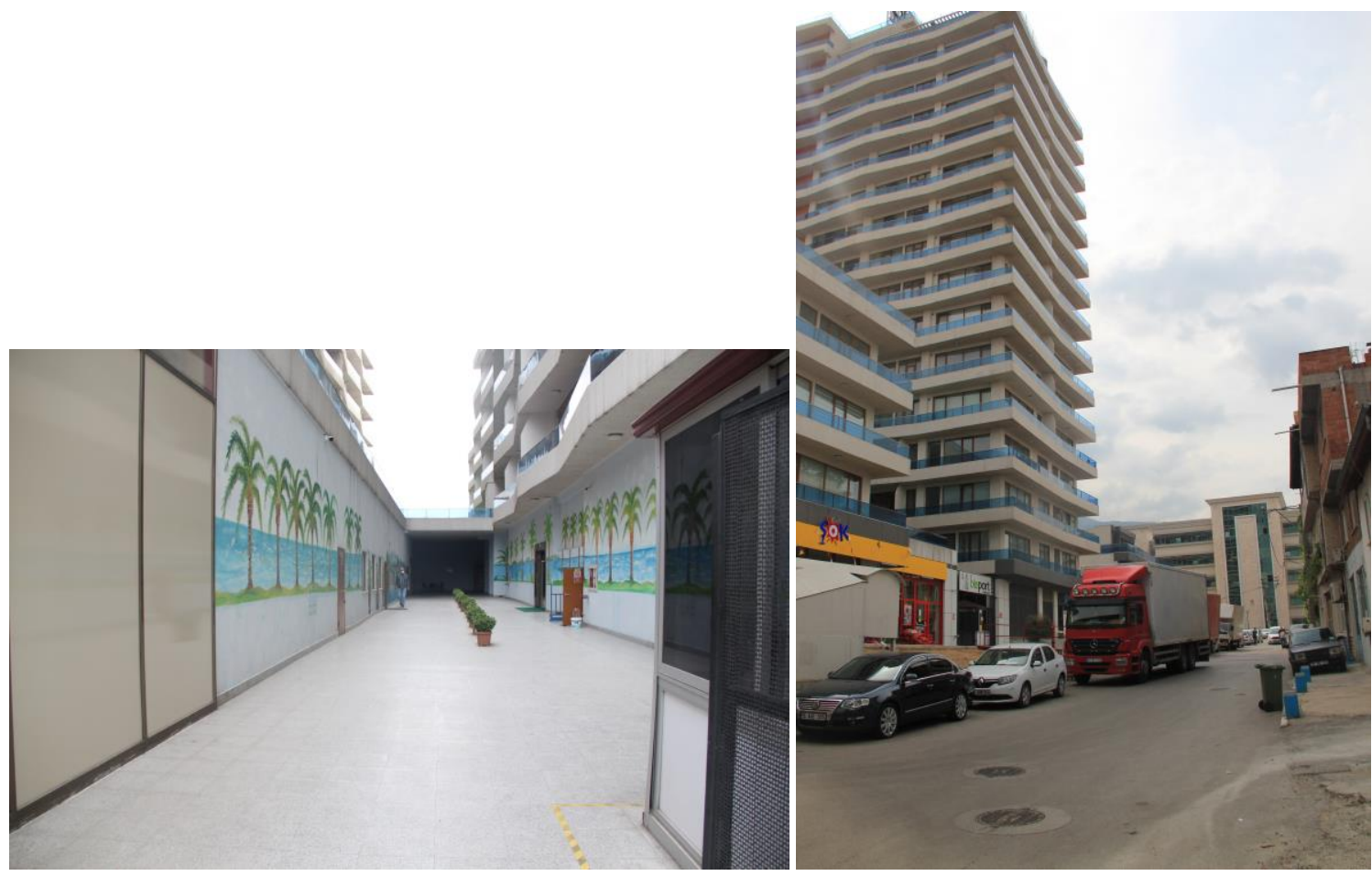

Figure 3: The inside and outside

\section{Source: Author}

Almost all children attract attention during the interviews to the blind spots that the structure creates (See figure 5). You say that in these areas you're afraid to play. In particular, children in the immediate vicinity of the project say that their parents warned them that these areas would not be approached. On the other hand, children dwell in gated housing estate developed by the urban regeneration project are saying that they can only walk among the closed door of the housing estate (see Figure 3 ).

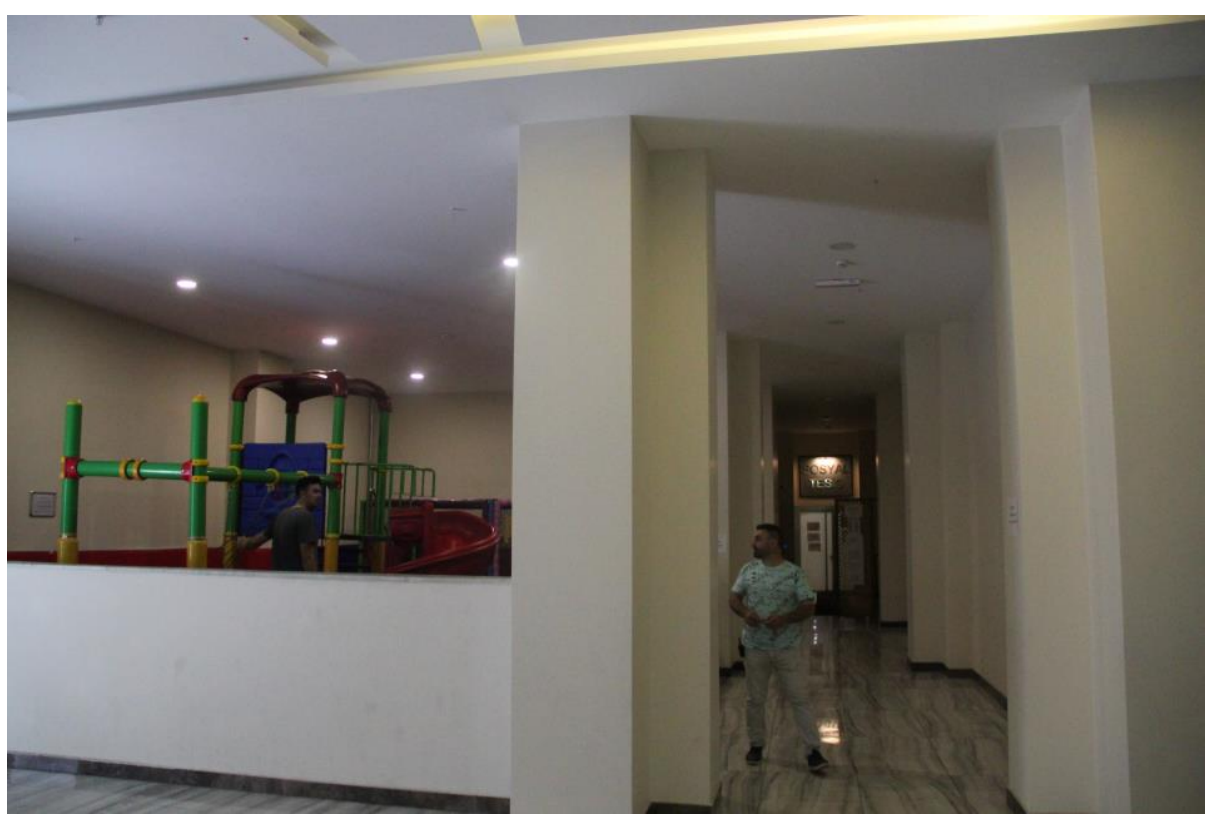

Figure 4: one of the two play-grounds in the project.

Source: Author 


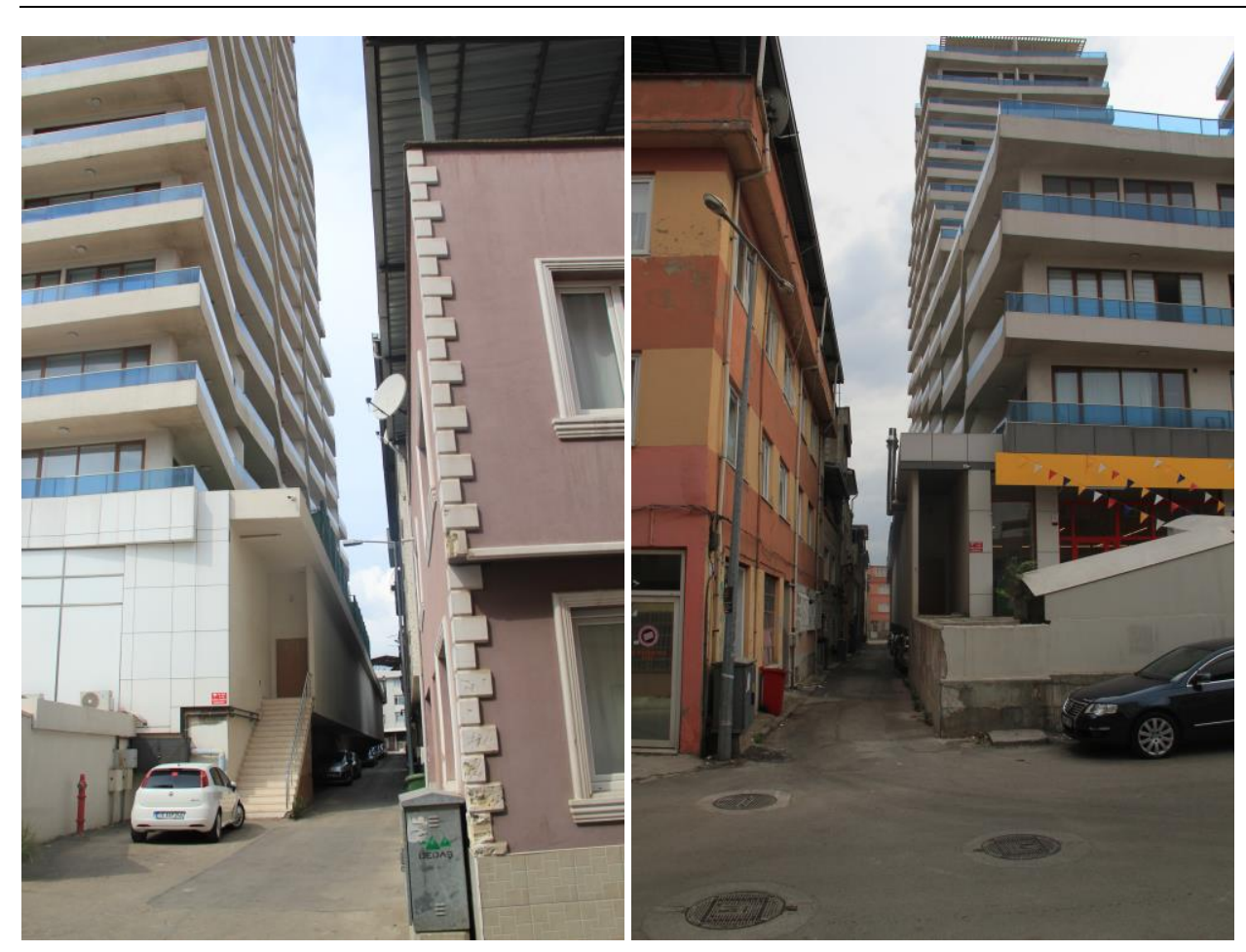

Figure 5: The blind-spot of the project

\section{Source: Author}

As expected, the children focus on the play-ground areas during the walking interviews. The surveyparticipant children live in the urban regeneration project complained about the size, material, location and quality of the children-play-ground areas. In the project, there are two play-grounds and each comprises a bubble pool and a plastic climbing unit. Moreover, these play-grounds located inside of the massive housing blocks just near the entrance of the building. They (the children of the project) view their use of play-ground is not satisfactory, in this respect. One of the children (A_UR) expresses this feeling as follows: "I wish they (the project developer and architects) had at least asked us when they were building the playgrounds". See Figure 4.

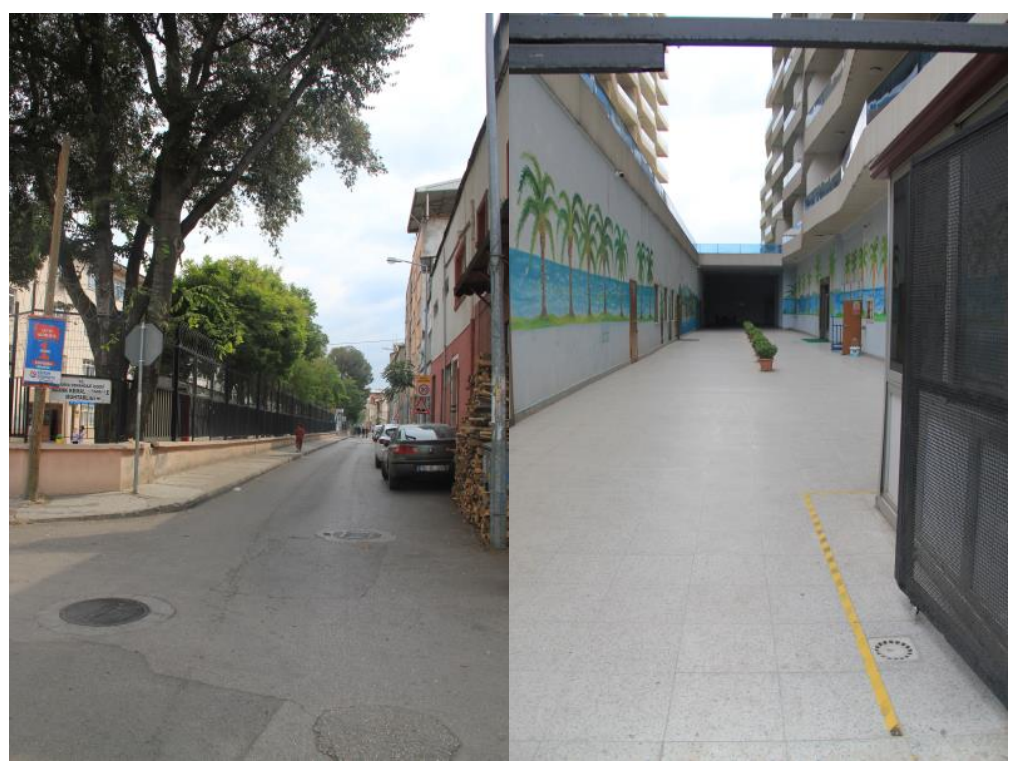

Figure 6: The playground inside and the school

Source: Author 
The children live surroundings of the project also state the playing areas. There are two play-grounds, one of the in the elementary school's plot, in the area (Figure 6). Their quality is comparatively moderate but at least, as one of the children mentioned (G_NUR): "They can get fresh air while playing here". However, one of the children (F_NUR), who has been using this playground for a long time, adds with an emphasis on safety: My mom does not send us (me and my little sister) to play here for the last few years, or rather, after the Syrian refugees started living here".

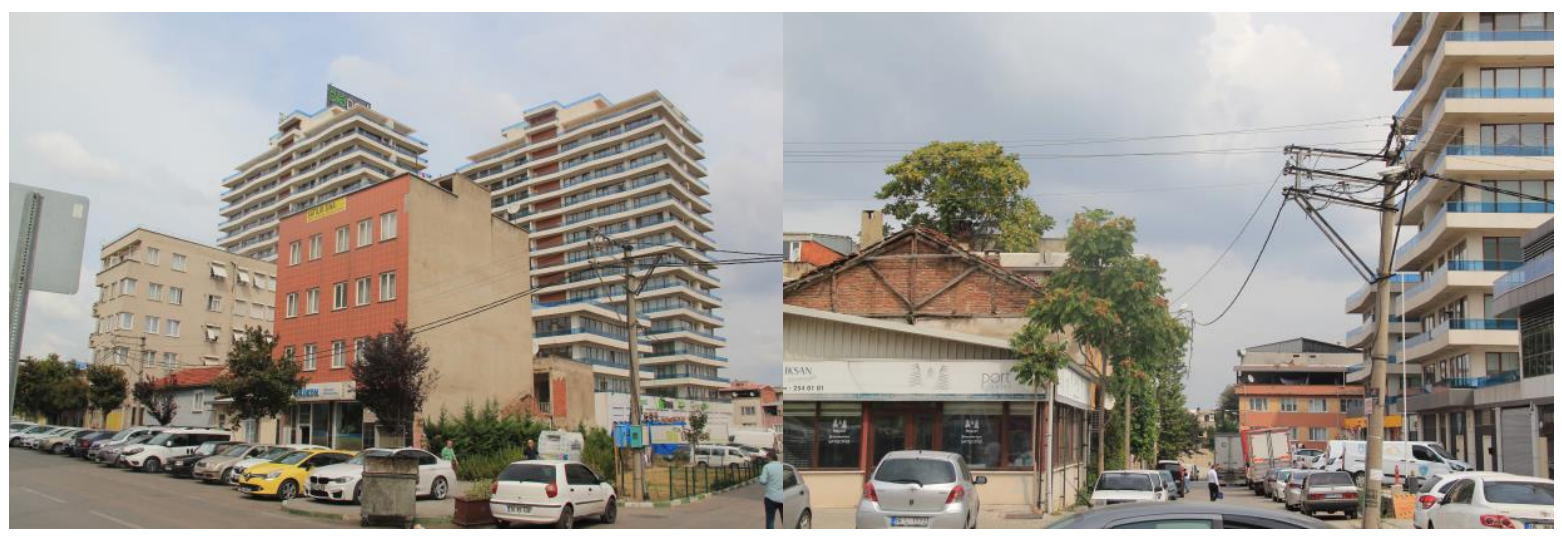

Figure 7: The project and its immediate surroundings

Source: Author

Although the focus with the children was mainly on play-grounds, the two survey-participants (D_UR and E_NUR) expressed their feelings about the place-making mechanisms and the development process of the project. As one of the family members whose old house transformed through urban regeneration project, D_UR stated that "we transformed our house, which was here before, through urban regeneration project. We have much more different home than before. Yes, I currently live on a higher floor and the view is beautiful, but we missed swinging in the mulberry tree in the garden. I wish they (the developer and the architects) had asked us what we wanted to remain. I would definitely like to have that tree." E_NUR expressed views parallel to the above: Earlier (before the project), when I woke up and looked out the window, I would greet my friend in the opposite house. Now, the sun does not fully enter our house and when you look through the window, there is only a concrete wall in front of it. If our voices were heard during the design process of the project, maybe this would not have happened."

\section{Concluding remarks and future research}

As previously stated, my goal is to hear the authentic voices of the children (who interact with the project both directly and indirectly) about the project-generated social and physical environments and restructure them from a broader socio-spatial perspective. In this study, the children's voices emphasized the importance of their home lives and demonstrated the lack of providing co-design process. Finally, inviting children to take part in activities of place-making regarding their interaction with living space environments (social as well as physical settings), their visions and their dreams gives them the opportunity to develop new identity, new places we did not previously imagine. To invite children to participate in co-design processes and make them publicly visible offers a platform to listen and take children seriously as valid urban stakeholders. The urban regeneration project now regards such activities as viable strategies for the involvement of children to gain an insight into their feelings, perceptions and perspectives. In this respect, the research highlights that if we -urban planners- want to make cities more human-centric, we must be unprejudiced and reconsider the role of the children.

With the realization of children's rights as individuals and their acceptance as distinct-urban users; listening to their perspectives and demands with place-making process, in this study "urban regeneration 
project", can contribute reliable and credible insights to the body of place-making and co-design researches. The literature raises the questions of how do children can contribute or linked with placemaking process. In this sense the researchers' agenda includes studies aimed at understanding child as well as vulnerable groups' attitudes, demands, and contributions to place-making processes as well as codesign process.

\section{Acknowledgements}

The views expressed in this paper do not reflect those of Bursa Technical University. I am responsible for all the contents, and all remaining errors are the author own.

\section{Funding}

There is no funding for the research.

\section{Conflict of Interest}

There is no conflict of interest.

\section{References}

Bronfenbrenner, U. (1979). The Ecology of Human Development. Cambridge: Harvard University Press

Chatterjee, S. (2015) Making Children Matter in Slum Transformations: Lessons from India's National Urban Renewal Mission, Journal of Urban Design, 20:4, 479-506, DOI: 10.1080/13574809.2015.1044506

Clark, A., \& Emmel, N. (2010). Using walking interviews. ESRC National Centre for Research Methods, 1-6. Retrieved from http://www.manchester.ac.uk/realities/resources/toolkits

Evans, J., \& Jones, P. (2011). The walking interview: Methodology, mobility and place. Applied Geography, 31(2), 849-858. https://doi.org/10.1016/j.apgeog.2010.09.005

James, A., \& Prout, A. (2015). Constructing and reconstructing childhood: Contemporary issues in the sociological study of childhood (classic ed.). London: Routledge.

King, A. C., \& Woodroffe, J. (2019). Walking interviews. Handbook of Research Methods in Health Social Sciences, (67), 1269-1290. https://doi.org/10.1007/978-981-10-5251-4_28

Kowalewski, M., \& Bartłomiejski, R. (2020). Is it research or just walking? Framing walking research methods as "non-scientific." Geoforum, 114(May), 59-65. https://doi.org/10.1016/j.geoforum.2020.06.002

Levy, R., \& Thompson, P. (2015). Creating buddy partnerships with 5- and 11-year old boys: A methodological approach to conducting participatory research with young children. Journal of Early Childhood Research, 13(2), 137-149.

Liepa-Zemeša, M., \& Hess, D. B. (2016). Effects of public perception on urban planning: Evolution of an inclusive planning system during crises in Latvia. Town Planning Review, 87(1), 71-92. https://doi.org/10.3828/tpr.2016.5

Mathews, H. \& Limb, M. (1999). Defining an agenda for the geography of children: Review and prospect. Progress in Human Geography, 23(1), pp. 61-90.

Pople, L., Rees, T. C. S. and G., Main, G., \& Bradshaw, J. (2015). The Good childhood Report 2015. Retrieved from http://www.childrenssociety.org.uk/sites/default/files/tcs/good_childhood_report_2013_final.pdf

Salamon, A. (2015). Ethical symmetry in participatory research with infants. Early Child Development and Care, 185(6), 1016-1030. 
Tisdall, E. K. M., \& Punch, S. (2012). Not so new? Looking critically at childhood studies. Children's Geographies, 10(3), 249-264

Quennerstedt, A., \& Quennerstedt, M. (2014). Researching children's rights in education: Sociology of childhood encountering educational theory. British Journal of Sociology of Education, 35(1), 115132.

Winge, L \& Lamm, B. (2019): Making the red dot on the map - bringing children's perspectives to the city planning agenda through visible co-design actions in public spaces, Cities \& Health, doi:10.1080/23748834.2019.1604931 